DOI: 10.17122/ntj-oil-2018-4-73-84

УДК 620.193:669.715

Д.Р. Латыпова, С.Е. Черепашкин, Е.В. Боев, О.Р. Латыпов (Уфимский

государственный нефтяной технический университет, г. Уфа, Российская Федерация)

\title{
ВЛИЯНИЕ $\mathrm{pH}$ СОЛЕВОГО КОНДЕНСАТА НА РАЗВИТИЕ ПИТТИНГОВОЙ КОРРОЗИИ АЛЮМИНИЕВЫХ СПЛАВОВ
}

\author{
Dina R. Latypova, Sergey E. Cherepashkin, Evgeniy V. Boev, Oleg R. Latypov \\ (Ufa State Petroleum Technological University, Ufa, Russian Federation) \\ SALT CONDENSATE pH EFFECT ON PITTING CORROSION \\ OF ALUMINUM ALLOYS
}

\begin{abstract}
Введение
Поздние этапы разработки нефтяных месторождений предусматривают применение технологий увеличения нефтеотдачи пласта, в связи с чем добыча нефти осуществляется в условиях ее высокой обводненности, что приводит к усиленной коррозии оборудования на объектах добычи, подготовки, хранения, транспорта и переработки нефти.

Высокая агрессивность технологических жидкостей связана с присутствием в них растворенных газов, механических примесей, ионов солей, водорастворимых нафтеновых и минеральных кислот и оснований, а также микроорганизмов, продукты жизнедеятельности которых вызывают активную биокоррозию металла. Согласно данным статистических исследований отказов и разрушений нефтегазового оборудования, можно отметить, что коррозия металла и образование ее продуктов, способствующих загрязнению транспортируемого сырья, представляют основные осложнения, существенно сокращающие его ресурс.
\end{abstract}

\section{Цели и задачи}

Оценка влияния значений $\mathrm{pH}$ коррозионной среды на развитие питтинговой коррозии в пластовой воде.

\section{Background}

The late stages of oil fields development include the technologies increasing oil recovery, and therefore oil production is carried out in conditions of its high water cut, which leads to increased equipment corrosion at production, preparation, storage, transport and processing facilities oil.

Technological fluids high aggressiveness is associated with the presence of dissolved gases, mechanical impurities, salt ions, watersoluble naphthenic and mineral acids and bases, as well as microorganisms whose lifeactivity products cause active biocorrosion of the metal. According to statistics of oil and gas equipment failures and destruction, it can be noted that corrosion of metal and the formation of its products, contributing to the transported raw materials contamination, represent the main complications that significantly reduce its resource.

\section{Aims and Objectives}

Impact assessment of corrosive environment $\mathrm{pH}$ on the pitting corrosion development in formation water.

() Латыпова Д.Р., Черепашкин С.Е., Боев Е.В., Латыпов О.Р., 2018 


\section{Результаты}

Исследования показали, что увеличение $\mathrm{pH}$ водно-солевого раствора, насыщенного ионами хлора, способствует существенному смещению стационарного электродного потенциала поверхности алюминиевого сплава (до 900 мВ) в отрицательном направлении. Это способствует усилению катодных реакций коррозии и пробою пассивной пленки. Пробой пассивной пленки вызывает развитие питтинговой коррозии. Согласно прогнозу, при увеличении $\mathrm{pH}$ до 14 возможно усиление скорости коррозии до 17 мм/год.

Характеристики и состав щелочного солевого конденсата требуют постоянного контроля. При значительных локальных увеличениях $\mathrm{pH}$ конденсата необходимо обеспечить защиту поверхности алюминиевого сплава лакокрасочным покрытием. Учет результатов исследования и следование приведенным рекомендациям позволят значительно увеличить ресурс понтонов, резервуаров и других конструкций при их эксплуатации в нефтегазовой отрасли.

\section{Results}

Studies have shown that an increase in the $\mathrm{pH}$ of a water-salt solution saturated with chlorine ions promotes the substantial shift of the aluminum alloy surface stationary electrode potential (up to $900 \mathrm{mV}$ ) in the negative direction. This contributes to the cathodic corrosion reactions enhancement and the breakdown of passive films. Passive film breakdown causes the pitting corrosion development. According to the forecast, if the $\mathrm{pH}$ is increased to 14 , the corrosion rate can be increased to $17 \mathrm{~mm} /$ year.

Characteristics and composition of alkaline salt condensate require constant monitoring. With significant local increase in the condensate $\mathrm{pH}$, it is necessary to protect the aluminum alloy surface with paint and varnish. Taking into account the study results and following the recommendations made will significantly increase the life of pontoons, reservoirs and other structures during their operation in the oil and gas industry.
Ключевые слова: скорость коррозии, питтинг, электродный потенциал, $\mathrm{pH}$, ионы хлора, пластовая вода
Key words: corrosion rate, pitting, electrode potential, $\mathrm{pH}$, chlorine ions, formation water
На современных предприятиях нефтегазовой отрасли резервуары различных конструкций, предназначенные для сбора и хранения нефти и нефтепродуктов, являются важным элементом в технологическом процессе добычи и переработки нефти. Поздние этапы разработки нефтяных месторождений предусматривают применение технологий увеличения нефтеотдачи пласта, в связи с чем добыча нефти осуществляется в условиях ее высокой обводненности. Наличие в технологических системах нефтепромыслов большого количества пластовой воды способствует развитию ряда серьезных осложнений при добыче нефти, которые приводят к усиленной коррозии оборудования на объектах добычи, подготовки, хранения, транспорта и переработки нефти [1-3].

Высокая агрессивность технологических жидкостей связана с присутствием в них растворенных газов $\left(\mathrm{H}_{2} \mathrm{~S}\right.$ и $\left.\mathrm{CO}_{2}\right)$, механических примесей, ионов солей $\left(\mathrm{Ca}^{2+}, \mathrm{Mg}^{2+}, \mathrm{Na}^{+}\right.$, $\left.\mathrm{SO}_{4}{ }^{2-}, \mathrm{Cl}^{-}\right)$, водорастворимых нафтеновых и минеральных кислот и оснований, а также микроорганизмов, продукты жизнедеятельности которых вызывают активную биокоррозию металла [2, 4-7]. Согласно данным статистических исследований отказов и разрушений нефтегазового оборудования, можно отметить, что коррозия металла и образование 
ее продуктов, способствующих загрязнению транспортируемого сырья, представляют основные осложнения, существенно сокращающие его ресурс.

В условиях действия нефтегазовых сред коррозионная стойкость алюминиевых сплавов значительно превосходит коррозионную стойкость конструкционной стали, поэтому с учетом хорошей технологичности делает перспективным их применение в качестве конструкционного материала для изготовления бурильных труб, змеевиков для нагревательных систем нефтеналивных барж, деталей и узлов буровых установок, а также резервуаров для хранения нефти и нефтепродуктов и их деталей. Однако несмотря на то, что алюминиевые сплавы обладают высокой коррозионной стойкостью во многих средах, встречающихся в нефтяной и газовой промышленности, на практике встречаются отдельные случаи возникновения коррозии, причины которой не всегда учитываются при проектировании, строительстве и эксплуатации резервуарных конструкций из алюминиевых сплавов [8, 9].

С целью повышения сроков эксплуатации всё большее применение находят понтоны и плавающие крыши из алюминиевых сплавов [10, 11]. Чистые нефтепродукты инертны по отношению к алюминию вследствие неэлектропроводного характера углеводородов [12]. Агрессивность нефти определяется содержанием примесей и воды. Высокую стойкость к сырой нефти и некоторым бензинам показали алюминиевые сплавы типа АМг и АК. В отсутствие хлористого водорода алюминиевые сплавы в парах нефтепродуктов более устойчивы, чем стали.

Средний срок службы ежегодно окрашиваемых стальных крыш составляет 8 лет, алюминиевые же крыши хорошо сохраняются без окраски в течение 15-20 лет. Разрушение днищ резервуаров ускоряется из-за скопления сернистого железа, образующегося в виде продуктов коррозии на стальных элементах, находящихся в паровоздушном пространстве резервуара [13-15]. Поэтому при изготовлении крыш из алюминия увеличивается срок службы и днищ резервуаров. Также главным преимуществом является легкость конструкции. При строительстве новых резервуаров легкий вес конструкции позволяет сэкономить на расходах для закладки фундамента и возведения стен резервуара.

Одна из проблем при хранении сырой нефти - высокая скорость испарения углеводородного сырья. Пары углеводородов и воды вызывают высокую скорость коррозии верхнего пояса и крыши резервуара. Наличие влажной пленки на поверхности металла провоцирует развитие коррозии по электрохимическому механизму, что приводит к появлению на ней микро- и макрогальванических элементов. Развитие электрохимической коррозии способствует не только разнородным значениям электродных потенциалов на поверхности конструкций, но и локальным изменениям таких коррозионных факторов, как $\mathrm{pH}$, концентрация и химический состав среды.

Для исключения образования агрессивной паровоздушной среды под крышей резервуара нашли широкое распространение понтоны, выполненные из алюминиевых сплавов, предотвращающие высокое испарение углеводородного сырья. Однако встречаются отдельные случаи отказов понтонов из алюминиевых сплавов, установленных в стальных резервуарах. В частности, были выявлены очаги питтинговой и язвенной коррозии алюминиевых поплавков понтонов под воздействием речной и пластовой воды при проведении гидроиспытаний резервуаров, а также настила понтонов при контакте с водой, загрязненной ржавчиной, попадающей из гидрозатворов дыхательной арматуры. Такие разрушения связаны в основном с нарушением сплошности пассивной пленки на алюминиевой поверхности.

Состояние и свойства пассивной пленки зависят от свойств алюминиевого сплава. На однофазных сплавах образуются сплошные пленки, придающие сплаву высокую коррозионную стойкость, в то время как на многофазных сплавах состав пленки может значительно измениться, провоцируя ее растрескивание и несплошности. Поэтому в алюминиевом сплаве является нежелательным наличие интерметаллидов железа, меди, никеля $\left(\mathrm{FeAl}_{3}, \mathrm{CuAl}_{2}, \mathrm{NiAl}_{3}\right)$, в 
местах локализации которых на поверхности сплава пассивная пленка не образуется [9]. Эти интерметаллиды обладают более положительным, чем у алюминия, стационарным электродным потенциалом $(-0,209,-0,37,-0,647$ В соответственно), за счет чего они увеличивают скорость катодного процесса коррозии сплава. В довольно широком интервале $\mathrm{pH}(4,5-8,0)$ скорость коррозии алюминия незначительна и не зависит от концентрации ионов водорода. Вместе с тем на кинетику формирования оксидных пленок и состав поверхностных соединений существенное влияние оказывает анионный состав электролита [11].

Вредное влияние на защитные свойства оксидной пленки оказывает наличие в водном растворе ионов меди, железа и никеля вследствие их катодного осаждения на алюминии [10].

Ионы галогенов, как правило, интенсивно разрушают защитную оксидную пленку. Особенно активное действие на защитную пленку оказывают ионы $\mathrm{F}^{-}$и $\mathrm{Cl}^{-}$, в меньшей степени действуют ионы $\mathrm{Br}^{-}$и J.' В растворах солей алюминий стоек в том случае, если соли обладают окислительными свойствами и способствуют образованию на его поверхности пассивной пленки [16].

Известно, что при повышении $\mathrm{pH}$ более 8 происходит усиление коррозии алюминиевых сплавов, в частности за счет ускоренного растворения пассивной пленки [17, 18]. При этом процесс коррозии характеризуется наличием в составе паровоздушного пространства солевого конденсата, поэтому определение коррозионной стойкости алюминиевых сплавов в подобных условиях весьма интересная задача.

Проведены потенциометрические исследования скорости коррозии алюминиевого сплава AK-4 в щелочных средах с различным показателем $\mathrm{pH}$, так как именно это способствует развитию локальных пробоев пассивной пленки, т.е. питтинговой коррозии. Исследования проводили на потенциостате «Elins P-30J» с линейной разверткой потенциала из катодной в анодную зону с помощью прижимной трехэлектродной ячейки (рисунок 1).

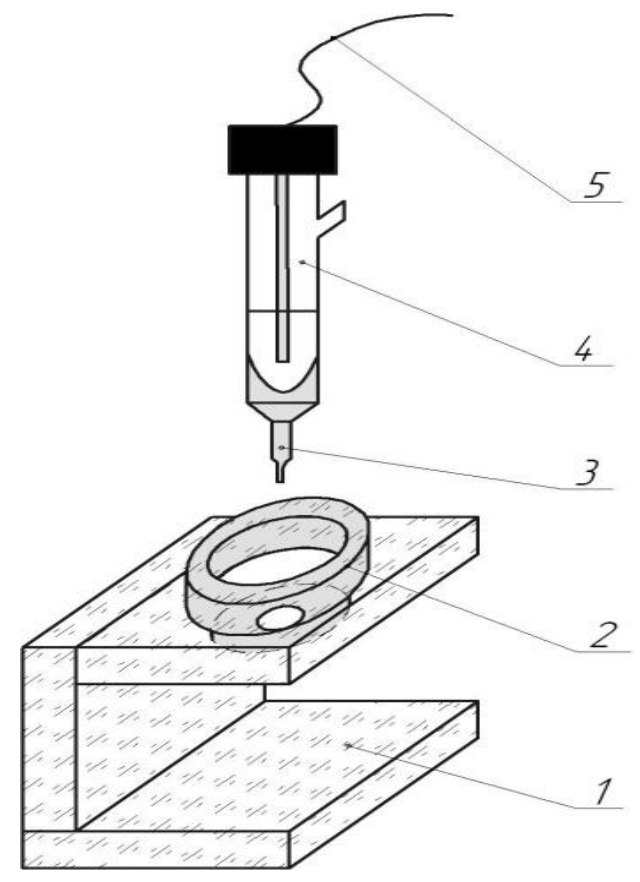

1 - корпус;

2 - стакан;

3 - капилляр Луггина;

4 - хлорсеребряный электрод сравнения;

5 - контактный провод

Рисунок 1. Схема прижимной электрохимической ячейки

Исследуемый образец помещали на нижнюю плоскость корпуса 1 и прижимали стаканом 2. В стакан наливался исследуемый электролит. В стакан помещали вспомогательный платиновый электрод. С помощью капилляра Луггина 3 хлорсеребряный электрод сравнения 4 имеет надежный контакт с исследуемым металлом. Электрод сравнения подключали к соответствующей клемме потенциостата посредством контактного провода 5 .

Исследуемой коррозионной средой служила модель пластовой воды № 3 (ГОСТ 9.502-82), содержащая 213 мг/дм ${ }^{3} \mathrm{Na}_{2} \mathrm{SO}_{4}$, $138 \mathrm{мг/дм}{ }^{3} \mathrm{NaHCO}_{3}$ и 333 мг/дм ${ }^{3} \mathrm{CaCl}_{2}$, так как ее химический состав соответствует составу пластовых вод большинства нефтяных месторождений РФ. Коррозионную среду с помощью $\mathrm{NaOH}$ доводили до необходимых значений $\mathrm{pH}$. На рисунках 2-5 показаны снятые поляризационные кривые для сплава AК-4 в коррозионной среде с различными значениями $\mathrm{pH}$. 


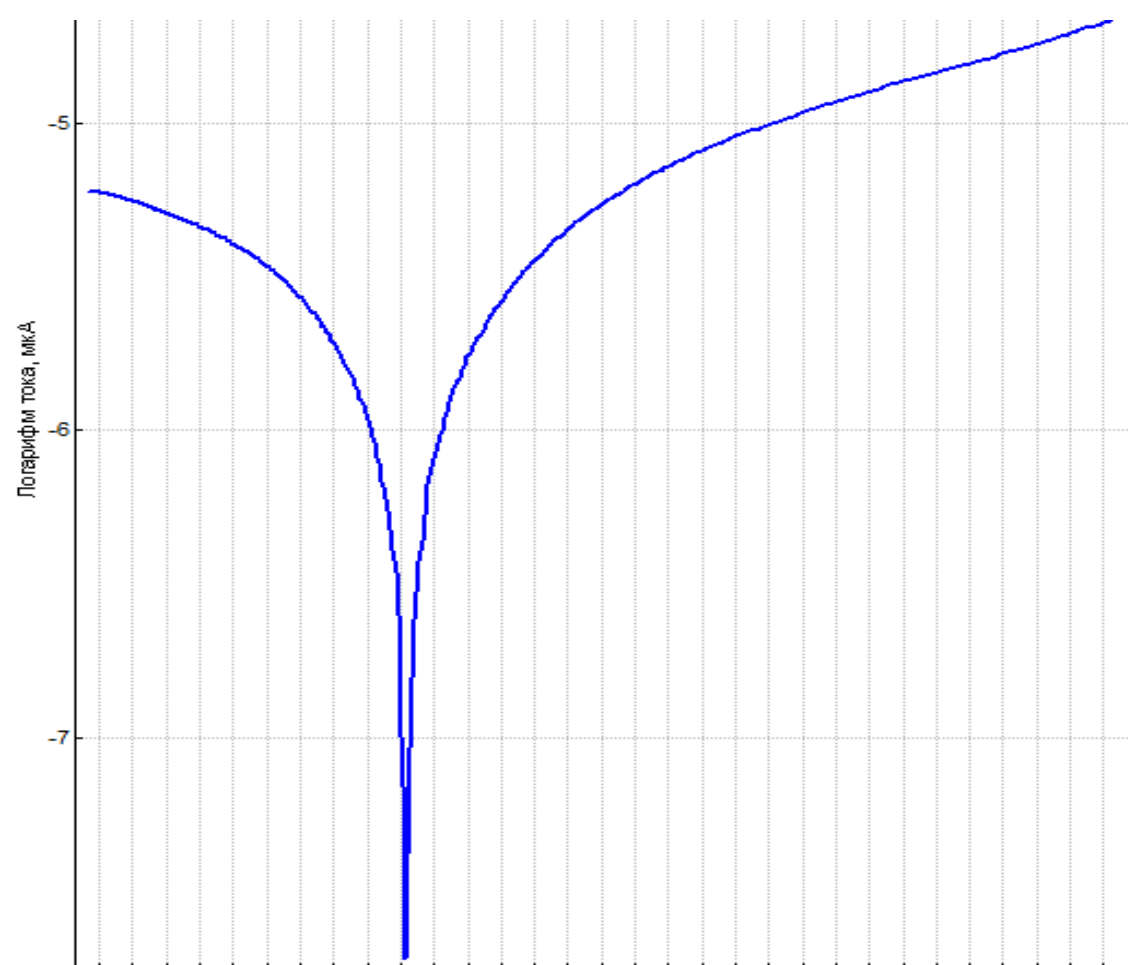

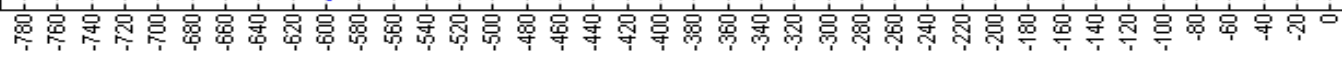
потенциал, мв

Рисунок 2. Поляризационные кривые для алюминиевого сплава AK-4 (pH = 9,45)

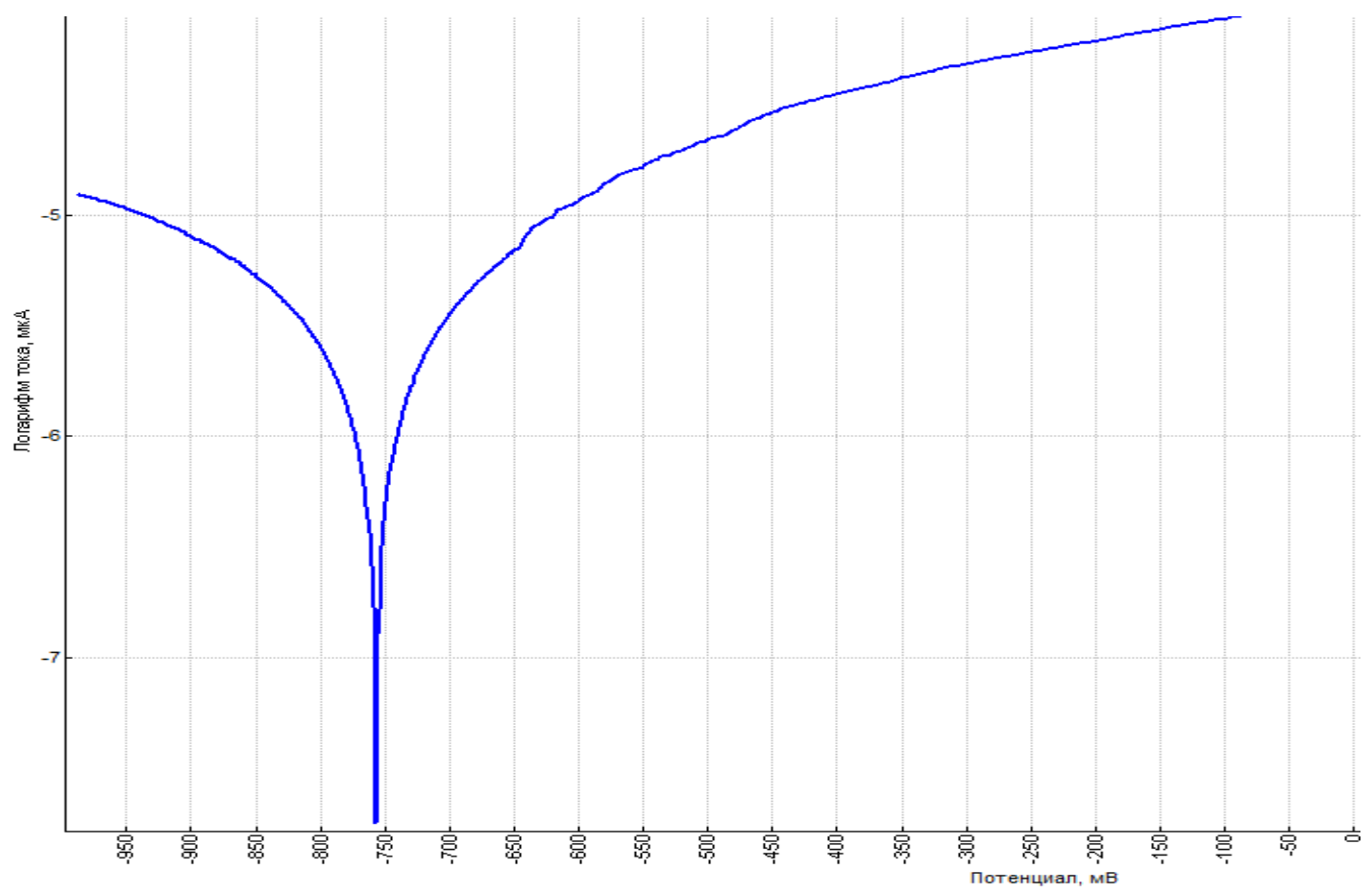

Рисунок 3. Поляризационные кривые для алюминиевого сплава АK-4 (pH = 10,80) 


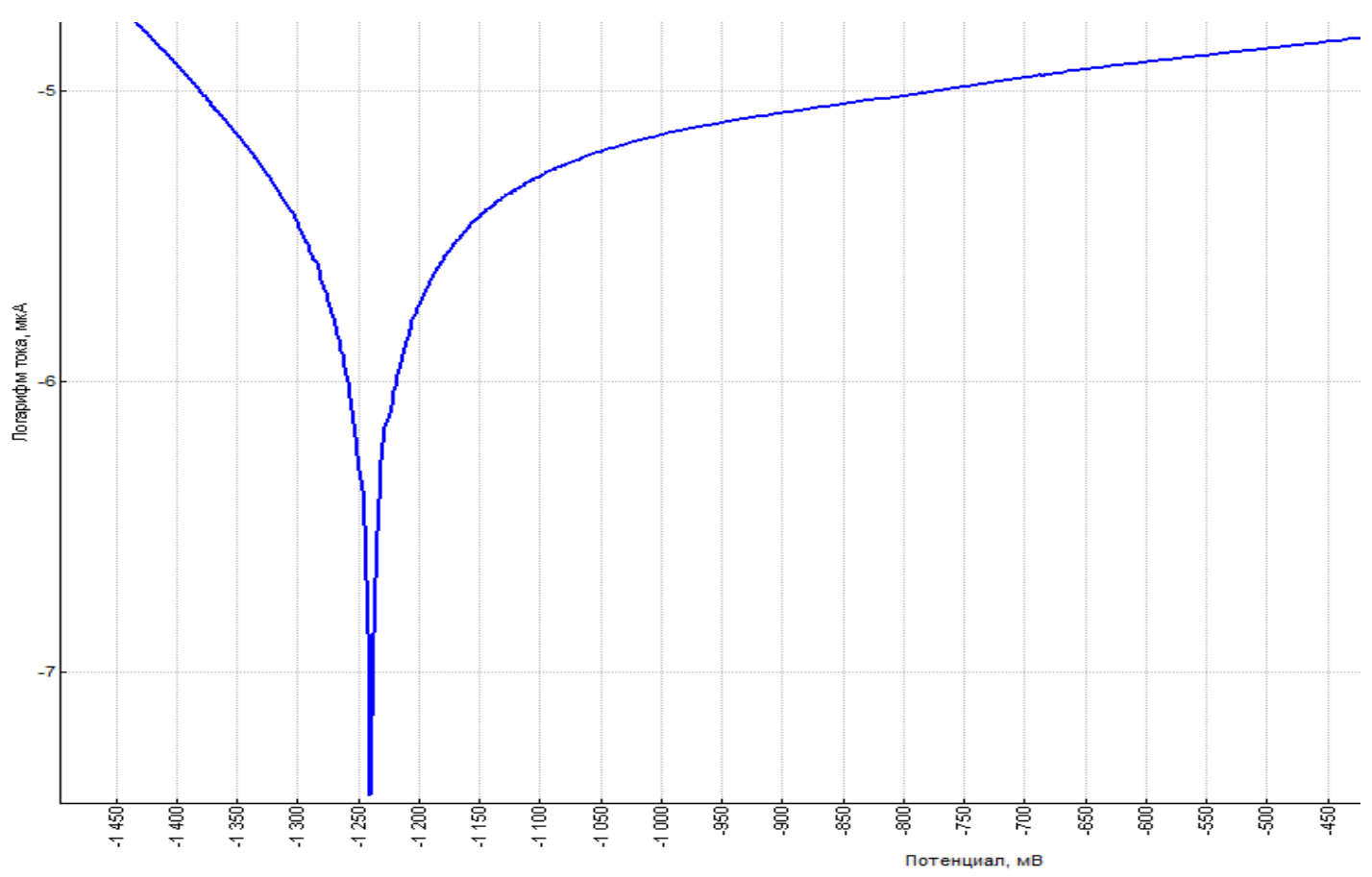

Рисунок 4. Поляризационные кривые для алюминиевого сплава AK-4 (pH=11,43)

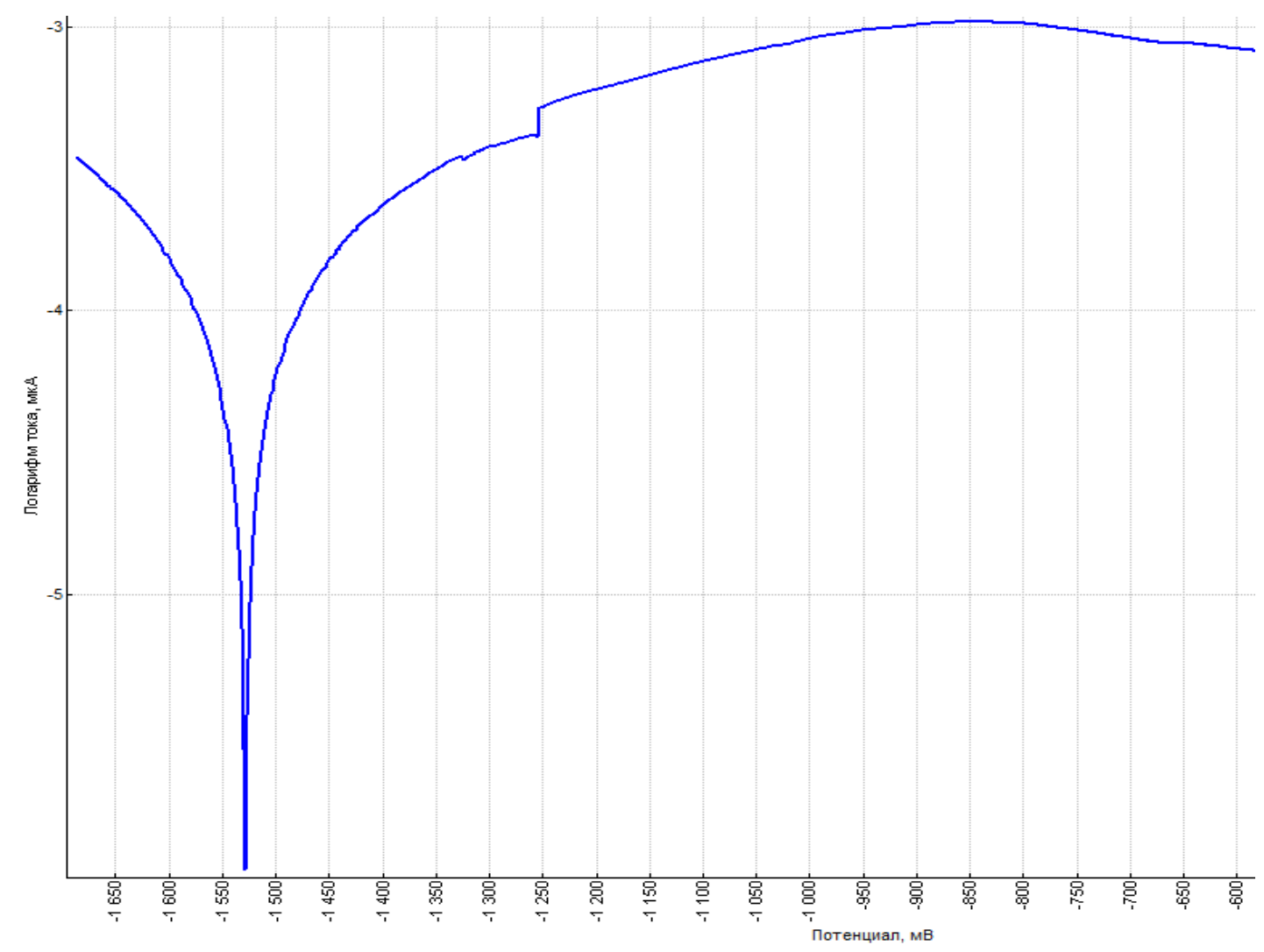

Рисунок 5. Поляризационные кривые для алюминиевого сплава AK-4 (pH = 12,88) 
Из приведенных рисунков 2-5 видно, что при изменении рН с 9,45 до 12,88 стационарный потенциал сплава изменился с минус 600 мВ до минус 1530 мВ. То есть, алюминиевый сплав становится более термодинамически неустойчивым и более активным, что сказывается и на скорости его растворения. Это вызвано растрескиванием пассивной пленки. В щелочных растворах $\mathrm{Al}^{3+}$ реагирует с $\mathrm{OH}^{-}$с образованием $\mathrm{AlO}_{2}^{-}$:

$$
\mathrm{Al}+\mathrm{NaOH}+\mathrm{H}_{2} \mathrm{O} \rightarrow \mathrm{NaAlO}+3 / 2 \mathrm{H}_{2} .
$$

Скорость коррозии алюминиевого сплава определяли с помощью экстраполя- ции тафелевских участков на поляризационных кривых по известным методикам [14]. Полученные данные сведены в таблицу 1 .

Таким образом, применение алюминиевых сплавов допускается в нейтральных средах.

Однако в условиях щелочного конденсата алюминиевые сплавы будут корродировать, и скорость коррозии может быть очень значительной.

В щелочной среде увеличение скорости коррозии алюминиевого сплава АK-4 в 6 раз больше по сравнению с близкой к нейтральной (рисунок 6).

Таблица 1. Скорость коррозии сплава АК в зависимости от $\mathrm{pH}$ раствора

\begin{tabular}{|c|c|c|c|c|}
\hline \multirow{2}{*}{$\begin{array}{c}\mathrm{pH} \\
\text { раствора }\end{array}$} & \multirow{2}{*}{$\begin{array}{l}\text { Стационарный } \\
\text { потенциал, В }\end{array}$} & \multicolumn{2}{|c|}{ Скорость коррозии } & \multirow{2}{*}{$\begin{array}{c}\text { Балл стойкости } \\
\text { (ГОСТ 13819-68) }\end{array}$} \\
\hline & & $\mathrm{K}_{\mathrm{m}}, \Gamma /\left(\mathrm{M}^{2} \mathrm{u}\right)$ & П (мм/год) & \\
\hline 9,45 & -600 & 0,027 & 0,087 & 5 \\
\hline 10,80 & -750 & 0,037 & 0,120 & 6 \\
\hline 11,43 & -1240 & 0,175 & 0,568 & 7 \\
\hline 12,88 & -1530 & 1,887 & 6,125 & 9 \\
\hline \multicolumn{5}{|c|}{ Плотность алюминия - $\rho_{A I}=2,7$ г/см ${ }^{3}$} \\
\hline
\end{tabular}

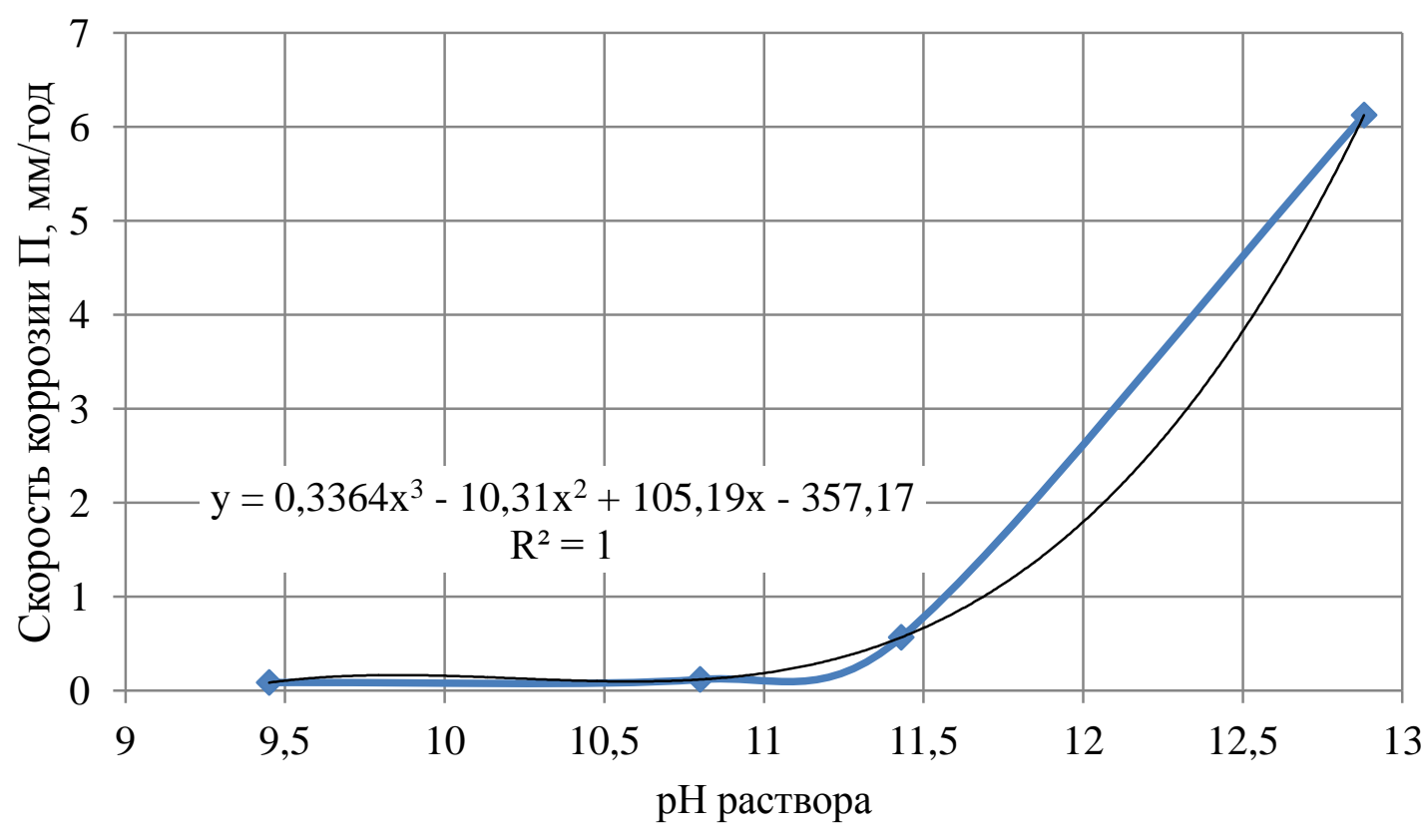

Рисунок 6. Зависимость скорости коррозии сплава АK-4 от значений рН 
Уравнение регрессии показало, что увеличение значений $\mathrm{pH}$ до экстремальных значений $(\mathrm{pH}=14)$ может вызвать увеличение скорости коррозии до 17,88 мм/год.

Применение электрохимических методов исследований для изучения свойств алюминия и его сплавов позволяет быстро и достаточно точно прогнозировать долговечность изделий из них.

Таким образом, явление подщелачивания катодных областей при электрохимическом процессе коррозии алюминиевого сплава способствует пробою пассивной пленки и развитию питтиноговой коррозии.

Применение летучих ингибиторов коррозии, имеющих щелочную природу (например амины и т.п.), несмотря на их высокую эффективность по отношению к стальным конструкциям следует реализовывать с тщательной осторожностью и подборкой рабочих дозировок [19-21].

Для исключения коррозионного разрушения рекомендуется осуществлять тщательный контроль свойств образующегося конденсата в сочетании с щелочестойким лакокрасочным покрытием [22-26].

\section{Список литературы}

1. Латыпов О.Р., Бугай Д.Е., Рябухина В.Н. Влияние компонентов пластовой воды на скорость коррозии нефтепромыслового оборудования // Проблемы сбора, подготовки и транспорта нефти и нефтепродуктов. 2016. Вып. 1 (103). C. $22-33$

2. Боев Е.В., Афанасенко В.Г., Латыпов О.Р., Черепашкин С.Е., Боева Н.И. Повышение качества водотопливных эмульсий // Уральский научный вестник. 2018. Т. 2, № 4. С. 19-22.

3. Latypov O.R. Reduction of Salt Deposits on the Surface of Oilfield Equipment by Management of Electrochemical Parameters of the Medium // Chemical and Petroleum Engineering. November 2015. Vol. 51, Issue 7. P. 522-525.

4. Овчинникова В.В., Латыпова Д.Р., Латыпов О.Р., Бугай Д.Е. Щелевая коррозия нефтезаводского оборудования в условиях действия ионов хлора // Матер. 68-й науч.-техн. конф. студентов, аспирантов и молодых ученых УГНТУ. Уфа: Издательство УГНТУ, 2017. Кн.1. С. 365.

\section{Выводы}

При повышении рН более 8 происходит значительное усиление коррозии алюминиевых сплавов, в частности за счет ускоренного растворения пассивной пленки. Наличие питтингообразующих ионов, например $\mathrm{Cl}^{-}$, оказывают активное действие на защитную пленку алюминиевого сплава, провоцируя питтинговую коррозию.

Результаты потенциометрических исследований показали, что при увеличении $\mathrm{pH}$ щелочного водно-солевого раствора на 3 единицы скорость коррозии увеличивается в 6 раз. Регрессионный анализ выявил значительное увеличение скорости коррозии в экстремально-щелочной области свыше 15 раз.

Наличие на поверхности алюминиевого сплава щелочного солевого конденсата не допустимо, требуется постоянный коррозионный мониторинг. В качестве способа защиты от питтинговой коррозии в щелочных условиях рекомендуется нанесение щелочестойкого лакокрасочного покрытия.

Учет результатов исследования и следование приведенным рекомендациям позволит значительно увеличить ресурс понтонов, резервуаров и других конструкций при их эксплуатации.

\section{References}

1. Latypov O.R., Bugai D.E., Ryabukhina V.N. Vliyanie komponentov plastovoi vody na skorost' korrozii neftepromyslovogo oborudovaniya [Effect of Formation Water Components on Corrosion Rate of Oilfield Equipment]. Problemy sbora, podgotovki i transporta nefti i nefteproduktov - Problems of Gathering, Treatment and Transportation of Oil and Oil Products, 2016, Issue 1 (103), pp. 22-33. [in Russian].

2. Boev E.V., Afanasenko V.G., Latypov O.R., Cherepashkin S.E., Boeva N.I. Povyshenie kachestva vodotoplivnykh emul'sii [Improving the Quality of Water-Fuel Emulsions]. Ural'skii nauchnyi vestnik - The Urals Scientific Herald, 2018, Vol. 2, No. 4, pp. 19-22. [in Russian].

3. Latypov O.R. Reduction of Salt Deposits on the Surface of Oilfield Equipment by Management of Electrochemical Parameters of the Medium. Chemical and Petroleum Engineering, November 2015, Vol. 51, Issue 7, pp. 522-525. DOI: dx.doi.org/10.1007/s10556-015-0079-z. 
5. Овчинникова В.В., Латыпов О.Р., Бугай Д.Е. Защита нефтезаводского оборудования от щелевой коррозии в условиях действия ионов хлора // Инновационные технологии в промышленности: образование, наука и производство: матер. Всеросс. науч.-практ. конф. с междунар. участием. Уфа: Изд-во «Нефтегазовое дело», 2016. C. 408-409.

6. Гареев А.Г., Насибуллина О.А., Ризванов Р.Г. Исследование водородного охрупчивания металла, приводящего к разрушению металлоконструкции // Проблемы сбора, подготовки и транспорта нефти и нефтепродуктов. 2017. Вып. 1 (107). C. 107-115.

7. Tyusenkov A.S., Rubtsov A.V., Tlyasheva R.R. Heat Resistance of Certain Structural Steels // Solid State Phenomena. 2017. Vol. 265. P. 868-872.

8. Гареев А.Г., Насибуллина О.А., Ризванов Р.Г. Исследование особенностей коррозионного растрескивания под напряжением образца стали X70, отобранного из очаговой зоны разрушения // Нефтегазовое дело. 2015. Т. 13. № 4. C. 244-248.

9. Латыпов О.Р., Кравцов В.В., Черепашкин С.Е. Теория и практика защиты от коррозии трубопроводов и резервуаров: учеб. пособие. Уфа: ООО «Монография», 2018. 542 с.

10. Абгалимова Г.Р., Кравцов В.В. Лабораторные испытания образцов из алюминиевых сплавов в волжской и уфимской воде // Матер. 68-й науч.-техн. конф. студентов, аспирантов и молодых ученых УГНТУ. Уфа: Издательство УГНТУ, 2017. Кн.1. С. 331.

11. Бакиева Э.Э., Шингаркина О.В., Шутов Н.В., Кравцов В.В., Макаренко О.А. Повышение износостойкости материалов уплотнений плавающих крыш резервуаров для хранения нефти // НЕФТЕГАЗОПЕРЕРАБОТКА - 2015: матер. Междунар. науч.-практ. конф. Уфа. 2015. C. 245-247.

12. Л Латыпов О.Р., Латыпова Д.Р., Бугай Д.Е., Рябухина В.Н. Предупреждение накопления электростатического заряда на поверхности нефтепромыслового оборудования // Проблемы сбора, подготовки и транспорта нефти и нефтепродуктов. 2016. Вып. 3 (105). С. 25-34.

13. Tyusenkov A.S. Chemical Resistance of Steel 13CrV (rus. 13XФA) // Journal of Chemical Technology and Metallurgy. 2017. Vol. 52. Iss. 4. P. 766-772.

14. Latypov O.R., Bugai D.E., Boev E.V. Method of Controlling Electrochemical Parameters of Oil Industry Processing Liquids // Chemical and Petroleum Engineering. July 2015. Vol. 51, Issue 3. P. 283-285.

15. Ризванов Р.Г., Муликов Д.Ш., Каретников Д.В., Черепашкин С.Е., Ширгазина Р.Ф. Коррозионная стойкость сварного соединения узла «труба - трубная решетка», полученного сваркой трением // Нанотехнологии в строительстве: научный интернет-журнал. 2017. Т. 9, № 4.
4. Ovchinnikova V.V., Latypova D.R., Latypov O.R., Bugai D.E. Shchelevaya korroziya neftezavodskogo oborudovaniya $v$ usloviyakh deistviya ionov khlora [Slit Corrosion of Refinery Equipment under the Action of Chloride Ions]. Materialy 68-i nauchno-tekhnicheskoi konferentsii studentov, aspirantov i molodykh uchenykh UGNTU [Materials of 68th Scientific-Technical Conference of Students, Graduate Students and Young Scientists of USPTU]. Ufa, USPTU Publishing House, 2017, Book 1, pp. 365. [in Russian].

5. Ovchinnikova V.V., Latypov O.R., Bugai D.E. Zashchita neftezavodskogo oborudovaniya ot shchelevoi korrozii $v$ usloviyakh deistviya ionov khlora [Protection of Refinery Equipment against Crevice Corrosion under the Action of Chloride Ions]. Materialy Vserossiyskoi nauchno-prakticheskoi konferentsii s mezhdunarodnym uchastiem "Innovatsionnye tekhnologii $v$ promyshlennosti: obrazovanie, nauka i proizvodstvo» [Materials of All-Russian Scientific-Practical Conference with International Participation «Innovative Technologies in Industry: Education, Science and Production». Ufa, Publishing House «Oil and Gas Business», 2016, pp. 408-409. [in Russian].

6. Gareyev A.G., Nasibullina O.A., Rizvanov R.G. Issledovanie vodorodnogo okhrupchivaniya metalla, privodyashchego $\mathrm{k}$ razrusheniyu metallokonstruktsii [Investigation of Hydrogen Embrittlement of Metal, Leading to the Destruction of Metal Structures]. Problemy sbora, podgotovki i transporta nefti i nefteproduktov - Problems of Gathering, Treatment and Transportation of Oil and Oil Products, 2017, Issue 1 (107), pp. 107115. [in Russian].

7. Tyusenkov A.S., Rubtsov A.V., Tlyasheva R.R. Heat Resistance of Certain Structural Steels. Solid State Phenomena, 2017. Vol. 265, pp. 868-872.

8. Gareyev A.G., Nasibullina O.A., Rizvanov R.G. Issledovanie osobennostei korrozionnogo rastreskivaniya pod napryazheniem obraztsa stali $X 70$, otobrannogo iz ochagovoi zony razrusheniya [Investigation of the Features of Stress Corrosion Cracking of an X70 Steel Sample Taken from a Focal Destruction Zone]. Neftegazovoe delo - Oil and Gas Business, 2015, Vol. 13, No. 4, pp. 244-248. [in Russian].

9. Latypov O.R., Kravtsov V.V., Cherepashkin S.E. Teoriya i praktika zashchity ot korrozii truboprovodov i rezervuarov [Theory and Practice of Corrosion Protection of Pipelines and Tanks]. Ufa, Monograph Publ., 2018. 542 p. [in Russian].

10. Abgalimova G.R., Kravtsov V.V. Laboratornye ispytaniya obraztsov iz alyuminievykh splavov v volzhskoi i ufimskoi vode [Laboratory Tests of Samples from Aluminum Alloys in the Volga and Ufa Waters]. Materialy 68-i nauchno-tekhnicheskoi konferentsii studentov, aspirantov i molodykh uchenykh UGNTU [Materials of 68th ScientificTechnical Conference of Students, Graduate Students and Young Scientists of USPTU]. Ufa, USPTU Publishing House, 2017, Book 1, pp. 331. [in Russian]. 
C. 97-115. DOI: dx.doi.org/10.15828/2075-85452017-9-4-97-115.

16. Пат. 2546736 РФ, МПК С 02 F 1/46. Способ управления водородным показателем $\mathrm{pH}$ и окислительно-восстановительным потенциалом Eh технологических жидкостей нефтепромыслов и устройство для его осуществления / Латыпов О.Р., Тюсенков А.С., Лаптев А.Б., Бугай Д.Е. (РФ). 2013157730/05; Заявлено 24.12.2013; Опубл. 10.04.2015, Бюл. № 10.

17. Овчинникова В.В., Печенкина М.Ю., Латыпов О.Р. Возможность формирования продуктов коррозии на углеродистых сталях в водносолевых растворах // Матер. 69-й науч.-техн. конф. студентов, аспирантов и молодых ученых УГНТУ: в 2 т. Уфа: Изд-во УГНТУ, 2018. Т. 1. C. 416.

18. Скуридин Н.Н., Латыпова Д.Р., Печенкина М.Ю., Латыпов О.Р., Бугай Д.Е., Рябухина В.Н. Формирование противокоррозионных пленок на металле нефтепромыслового оборудования методом поляризации технологических жидкостей // Нефтяное хозяйство. 2018. № 5. С. 84-86.

19. Миракян С.М., Латыпов О.Р., Бугай Д.Е., Раскильдина Г.З. Поляризационные исследования ингибирующей эффективности некоторых вторичных аминов // Башкирский химический журнал. 2017. Т. 24, № 2. С. 42-45.

20. Лаптев А.Б., Спивак А.Е., Черепашкин С.Е., Цыпышев О.Ю., Бугай Д.Е., Ахияров Р.Ж., Рябухина В.Н. Ингибирующая способность консервационного состава на основе имидазолинов в кислых водных средах // Проблемы сбора, подготовки и транспорта нефти и нефтепродуктов. 2015. Вып. 4 (102). С. 139-150.

21. Faritov A.T., Rozhdestvenskii Yu.G., Yamshchikova S.A., Minnikhanova E.R., Tyusenkov A.S. Improvement of the Linear Polarization Resistance Method for Testing Steel Corrosion Inhibitors // Russian Metallurgy (Metally). 2016. № 11. P. 1035-1041.

22. Бакиева Э.Э., Шангаркина О.В., Кравцов В.В., Макаренко О.А., Ибрагимов И.Г. Износостойкая композиция для окраски внутренней поверхности стальных резервуаров с плавающими крышами // Монтажные и специальные работы в строительстве. 2015. № 4. С. 23-26.

23. Кравцов В.В., Ишмухаметов Б.Х. Влияние летучего ингибитора на лакокрасочное покрытие в системах комбинированной защиты от коррозии внутренней поверхности стального резервуара // Химическая техника. 2014. № 2. С. 18.

24. Хуссейн А.Г., Кравцов В.В. Влияние летучего ингибитора коррозии на защитные свойства лакокрасочного покрытия // Матер. 64-й науч.техн. конф. студентов, аспирантов и молодых ученых УГНТУ. Уфа: Издательство УГНТУ, 2013. C. 220-221.

25. Кравцов В.В., Сырлыбаев Х.Р., Шингаркина О.В., Алексеева Н.А. Оценка остаточной защитной способности лакокрасочных покрытий на
11. Bakieva E.E., Shingarkina O.V., Shutov N.V., Kravtsov V.V., Makarenko O.A. Povyshenie iznosostoikosti materialov uplotnenii plavayushchikh krysh rezervuarov dlya khraneniya nefti [Increasing the Wear Resistance of Seal Materials for Floating Roofs of Oil Storage Tanks]. Materialy Mezhdunarodnoi nauchno-prakticheskoi konferentsii «NEFTEGAZOPERERABOTKA 2015» [Materials of International ScientificPractical Conference «OIL \& GAS PROCESSING - 2015»]. Ufa, 2015, pp. 245-247. [in Russian].

12. Latypov O.R., Latypova D.R., Bugai D.E., Ryabukhina V.N. Preduprezhdenie nakopleniya elektrostaticheskogo zaryada na poverkhnosti neftepromyslovogo oborudovaniya [Prevention of Accumulation of Electrostatic Charge on the Surface of Oilfield Equipment]. Problemy sbora, podgotovki i transporta nefti i nefteproduktov - Problems of Gathering. Treatment and Transportation of Oil and Oil Products, 2016, Issue 3 (105), pp. 25-34. [in Russian].

13. Tyusenkov A.S. Chemical Resistance of Steel 13CrV (rus. 13XФA). Journal of Chemical Technology and Metallurgy, 2017, Vol. 52, No. 4, pp. 766-772.

14. Latypov O.R., Bugai D.E., Boev E.V. Method of Controlling Electrochemical Parameters of Oil Industry Processing Liquids. Chemical and Petroleum Engineering, July 2015. Vol. 51, Issue 3, pp. 283285. DOI: dx.doi.org/10.1007/s10556-015-0038-8.

15. Rizvanov R.G., Mulikov D.Sh., Karetnikov D.V., Cherepashkin S.E., Shirgazina R.F. Corrosion Resistance of «Tube - Tubesheet» Weld Joint Obtained by Friction Welding. Nanotehnologii $v$ stroitel'stve - Nanotechnologies in Construction, 2017, Vol. 9, No. 4, pp. 97115. DOI: dx.doi.org/10.15828/2075-8545-2017-9-4-97115. [in Russian].

16. Latypov O.R., Tysenkov A.S., Laptev A.B., Bugai D.E. Sposob upravleniya vodorodnym pokazatelem pH i okislitel'no-vosstanovitel'nym potentsialom Eh tekhnologicheskikh zhidkostei neftepromyslov i ustroistvo dlya ego osushchestvleniya [A Method for Controlling a Hydrogen $\mathrm{pH}$ Index and a Redox Potential Eh of Oilfield Technological Fluids and a Device for its Implementation]. Patent RF, No. 2546736, 2015. [in Russian].

17. Ovchinnikova V.V., Pechenkina M.Yu., Latypov O.R. Vozmozhnost' formirovaniya produktov korrozii na uglerodistykh stalyakh $v$ vodno-solevykh rastvorakh [The Possibility of Forming Corrosion Products on Carbon Steels in Water-Salt Solutions]. Materialy 69-i nauchno-tekhnicheskoi konferentsii studentov, aspirantov i molodyh uchenykh UGNTU [Materials of 69th Scientific-Technical Conference of Students, Graduate Students and Young Scientists of USPTU]. Ufa, USPTU Publishing House, 2018, Book 1, pp. 416. [in Russian].
18. Skuridin N.N., Latypova D.R., Pechenkina M.Yu., Latypov O.R., Bugai D.E., Ryabukhina V.N. Formirovanie protivokorrozionnykh plenok na metalle neftepromyslovogo oborudovaniya metodom polyarizatsii tekhnologicheskikh zhidkostei [Formation of Anticorrosive Films on the Metal of Oilfield Equipment by the Method of Polarization of Pro- 
внутренней поверхности стальных резервуаров // Территория «Нефтегаз». 2012. № 3. С. 36-39.

26. Макаренко О.А., Кравцов В.В. Определение защитных свойств лакокрасочного покрытия внутренней поверхности резервуаров // Известия высших учебных заведений. Нефть и газ. 2010. № 1. C. 112-115. cess Liquids]. Neftyanoe khozyaistvo - Oil industry, 2018, No. 5, pp. 84-86. DOI: 10.24887/0028-24482018-5-84-86. [in Russian].

19. Mirakyan S.M., Latypov O.R., Bugai D.E., Raskildina G.Z. Polyarizatsionnye issledovaniya ingibiruyushchei effektivnosti nekotorykh vtorichnykh aminov [Polarization Studies of the Inhibitory Efficacy of Some Secondary Amines]. Bashkirskii khimicheskii zhurnal - Bashkir Chemical Journal, 2017, Vol. 24, No. 2, pp. 42-45. [in Russian].

20. Laptev A.B.,

Spivak

A.E., Cherepashkin S.E., Tsypyshev O.Yu., Bugai D.E., Akhiyarov R.Zh., Ryabukhina V.N. Ingibiruyushchaya sposobnost' konservatsionnogo sostava na osnove imidazolinov v kislykh vodnykh sredakh [The Inhibitory Ability of the Conservation Composition Based on Imidazolines in Acidic Aqueous Media]. Problemy sbora, podgotovki i transporta nefti i nefteproduktov Problems of Gathering, Treatment and Transportation of Oil and Oil Products, 2015. Issue 4 (102). pp. 139-150. [in Russian].

21. Faritov A.T., Rozhdestvenskii Yu.G., Yamshchikova S.A., Minnikhanova E.R., Tyusenkov A.S. Improvement of the Linear Polarization Resistance Method for Testing Steel Corrosion Inhibitors. Russian Metallurgy (Metally), 2016, No. 11, pp. 1035-1041.

22. Bakieva E.E., Shangarkina O.V., Kravtsov V.V., Makarenko O.A., Ibragimov I.G. Iznosostoikaya kompozitsiya dlya okraski vnutrennei poverkhnosti stal'nykh rezervuarov s plavayushchimi kryshami [Wear-Resistant Composition for Painting the Inner Surface of Steel Tanks with Floating Roofs]. Montazhnye i special'nye raboty $v$ stroitel'stve - As sembly and Special Works in Construction, 2015, No. 4, pp. 23-26. [in Russian].

23. Kravtsov V.V., Ishmukhametov B.Kh. Vliyanie letuchego ingibitora na lakokrasochnoe pokrytie $v$ sistemakh kombinirovannoi zashchity ot korrozii vnutrennei poverhnosti stal'nogo rezervuara [Influence of the Volatile Inhibitor on the Paint Coating in Systems of Combined Corrosion Protection of the Inner Surface of a Steel Tank]. Khimicheskaya tekhnika - Chemical Engineering, 2014, No. 2, pp. 18. [in Russian].

24. Hussain A.G., Kravtsov V.V. Vliyanie letuchego ingibitora korrozii na zashchitnye svoistva lakokrasochnogo pokrytiya [Effect of a Volatile Corrosion Inhibitor on the Protective Properties of Paintwork]. Materialy 64-i nauchno-tekhnicheskoi konferentsii studentov, aspirantov i molodykh uchenykh UGNTU [Materials of 64th scientifictechnical Conference of Students, Graduate Students and Young Scientists of USPTU]. Ufa: USPTU Publishing House, 2013. pp. 220-221. [in Russian].

25. Kravtsov V.V., Syrlybaev H.R., Shingarkina O.V., Alekseeva N.A. Otsenka ostatochnoi zashchitnoi sposobnosti lakokrasochnykh pokrytiy na vnutrennei poverkhnosti stal'nykh rezervuarov [Estimation of Residual Protective Ability of Paint Coatings on the Inner Surface of Steel Tanks]. Territoriya Neftegaz - Neftegaz Territory, 2012, No. 3, pp. 36-39. [in Russian]. 


\author{
Авторы \\ - Латыпова Дина Ринатовна \\ Уфимский государственный нефтяной \\ технический университет \\ Преподаватель кафедры «Технология нефтяного \\ аппаратостроения» \\ Российская Федерация, 450062, г. Уфа, \\ ул. Космонавтов, 1 \\ e-mail: d.r.latypova@mail.ru
}

- Черепашкин Сергей Евгеньевич, канд. техн. наук

Уфимский государственный нефтяной

технический университет

Доцент кафедры «Технология нефтяного

аппаратостроения»

Российская Федерация, 450062, г. Уфа,

ул. Космонавтов, 1

e-mail: scull@bk.ru

- Боев Евгений Владимирович, канд. техн. наук

Филиал Уфимского государственного нефтяного технического университета в г. Стерлитамак

Доцент кафедры «Оборудование

нефтехимических заводов»

Российская Федерация, Республика

Башкортостан, 453118, г. Стерлитамак,

пр. Октября, 2

e-mail:9196011116@mail.ru

\footnotetext{
- Латыпов Олег Ренатович, д-р техн. наук Уфимский государственный нефтяной технический университет Профессор кафедры «Технология нефтяного аппаратостроения»

Российская Федерация, 450062, г. Уфа,

ул. Космонавтов, 1

e-mail: o.r.latypov@mail.ru
}

26. Makarenko O.A., Kravtsov V.V. Opredelenie zashchitnykh svoistv lakokrasochnogo pokrytiya vnutrenney poverkhnosti rezervuarov [Determination of the Protective Properties of the Paint Coating of the Internal Surface of Tanks]. Izvestiya vysshikh uchebnykh zavedenij. Neft' i gaz. - News of Higher Educational institutions. Oil and Gas, 2010, No. 1, pp. 112-115. [in Russian].

\section{The Authors}

- Latypova Dina R.

Ufa State Petroleum Technological University

Lecturer of Petroleum Technology Equipment

Department

1, Kosmonavtov str., Ufa, 450062 ,

Russian Federation

e-mail: d.r.latypova@mail.ru

- Cherepashkin Sergey E., Candidate of Engineering Sciences

Ufa State Petroleum Technological University

Assistant Professor of Petroleum Technology

Equipment Department

1, Kosmonavtov str., Ufa, 450062,

Russian Federation

e-mail: scull@bk.ru

- Boev Evgeniy V., Candidate of Engineering

Sciences

Sterlitamak Affiliate of Ufa State Petroleum

Technological University

Assistant Professor of Equipment of Petrochemical

Plants Department

2, October ave., Sterlitamak, 453118

Republic of Bashkortostan, Russian Federation

e-mail: 9196011116@mail.ru

- Latypov Oleg R., Doctor of Engineering Sciences Ufa State Petroleum Technological University

Professor of Petroleum Technology Equipment Department

1, Kosmonavtov str., Ufa, 450062,

Russian Federation

e-mail: o.r.latypov@mail.ru 